\title{
ФилосоФия
}

DOI 10.17805/ggz.2017.4.8

\section{Этическое и эстетическое отношение к природе в различных культурах и религиях}

\author{
И. С. ИВАНОВА
}

МОСКОВСКИЙ ГУМАНИТАРНЫЙ УНИВЕРСИТЕТ

В статье рассматривается отношение к природе в различных культурах, выявляется общая основа уважительного отношения флоре и фауне. Автор показывает применение категорического императива И. Канта к решению экологических вопросов, рассказывает, что последствия гибели личности, выбирающей этические установки И. Канта, могут привести к экологическим катастрофам. Автор показывает, что можно способствовать улучшению экологии через воспитание любящей природу и ответственной личности нового типа.

Ключевые слова: экология; природа; культура; обожествление; религия; трансформация; образ; искусство; воспитание

\section{Ethical and Aesthetic Attitude to Nature in Different Cultures and Religions}

\author{
I. S. IVANOVA \\ MOSCOW UNIVERSITY FOR THE HUMANITIES
}

The article examines the attitude to nature in different cultures and reveals a common ground of respect for flora and fauna. The author shows the application of the categorical imperative of Kant to the solution of environmental issues and argues that the consequences of the death of the person choosing the ethical attitudes of Kant can lead to environmental disasters. The author shows that it is possible to contribute to environmental improvement through development of a responsible personality of a new type who loves nature.

Keywords: ecology; nature; culture; idolization; religion; transformation; image; art; education

Предметом исследования в данной статье является отношение к природе в различных культурах, представленное в художественных произведениях, религиях разных стран.

Загрязнение среды обитания человека, исчезновение целых видов животных и птиц, изменение климата и многие негативные для человека природные процессы не воспринимаются сегодня как чрезвычайные, хотя таковыми являются, и, например, в современном мире «существует опасность возникновения новых заболеваний наподобие СПИАа» (Костина, 2005: 102). В этой тревожной экологической обстановке приобретает особое значение ответственность человека за свои поступки. А. И. Шен- 
дрик в своей работе «Глобализация в системе культурологических координат» отмечал, что гибнет личность, принимающая как вектор развития «этические установки И. Канта» (Шендрик, 2004: 70). Все меньше становится людей, которые живут по категорическому императиву, одной из частей которого являются утверждение о поступке в соответствии с тем, чтобы максима воли того, кто этот поступок совершает, в любое время могла стать принципом всеобщего законодательства (Кант, 1995). Известно, что путь проверки желания при помощи данного императива следующий: надо представить гипотетическую ситуацию, в которой желаемое осуществилось не только одним человеком, но и всеми людьми, попавшими в аналогичную ситуацию. Если человечеству при этом будет нанес ен вред, не надо делать предполагаемый поступок. Применительно к воспитанию правильного отношения к экологии категорический императив можно применять очень широко: от объяснения детям и некоторым безответственным взрослым, почему нельзя рвать цветы, засорять леса, парки, водоемы, убивать животных до решения производственных проблем и профессиональной этики, идей того, что преступно не устанавливать очистные сооружения на вредных производствах и надо беречь атмосферу, экосферу, недопустимо безответственно относиться к своей работе. Всеобщие правила отношения к природе у людей подкрепляются национальными традициями, культурными этическими и эстетическими нормами.

Россия всегда интересовалась культурой других народов и бескорыстно, и с целью духовного обмена опытом, содружества, и с желанием взять самое лучшее. В этом плане интересно в работе Э. Фромма «Иметь или быть» выявить аргументацию автора относительно темы отношения к природе в разных культурах и религиях. Она в основном основана на фактах поэзии, где Фромм ищет подтверждение своей позиции. Так, ученый приводит стихотворение А. Теннисона, в котором англичанин, увидев прекрасный цветок, в жажде познания истины и красоты мироздания губит его. Э. Фромм отмечает, что первым желанием лирического героя Теннисона было стремление «обладать» цветком. Он срывает цветок целиком, вместе с корнями. И хотя Теннисон завершает стихотворение глубокомысленными рассуждениями о том, что этот цветок может помочь ему проникнуть в суть природы Бога и человека, само растение обрекается на смерть, становится жертвой проявленного таким образом интереса к нему. Героя стихотворения Теннисона можно сравнить с типичным западным ученым, который в поисках истины расчленяет, т. е. уничтожает живое существо (Фромм, 2007).

Причину гибели цветка Фромм видит в жажде обладания, которую он относит к недостаточно развитым культурам и религиям. Если брать религии, то это верования язычников, допускавшие человеческие и животные жертвоприношения. Если говорить о культурах, то апофеоз жажды обладания приходится на первобытнообщинный строй. Чем выше внутренняя культура человека, тем дальше он от жертвоприношений живых существ. Известно, что древнеегипетский фараон Эхнатон, отменив культ Амона и провозгласив служение Атону, отменил и принесение в жертву богам животных. Представитель другой культуры и другой эпохи японский поэт Бас е, увидев цветок, хочет просто его созерцать и стать с ним единым целым, на что обращает внимание Фромм. Такая позиция близка религии дзен-буддизма, не- даром

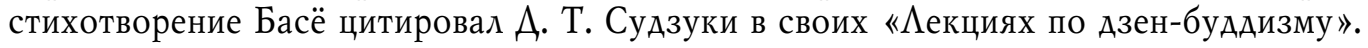
Здесь можно провести параллель с толерантностью по отношениям к людям других стран и народов, всем видам плодотворного диалога, которые ведут миру. 
B стихотворении на ту же тему немецкий поэт XVIII-XIX вв. Гёте поступает иначе: выкапывает цветок с корнями и пересаживает его в свой сад, чтобы сохранить цветку жизнь (там же). Это можно сравнить с завоевательными войнами Александра Македонского, который частично оставлял покоренным народам их культуру. Но у Э. Фромма, конечно, идет речь об отношении к объекту любви и исследования не в переносном смысле, а в прямом - это отношение к живой природе, ее восприятию и исследованию.

Надо заметить, что человек варварским методом исследовал природу. Например, клонирование человека в криминальных обществах повышает уровень преступности, когда идет охота за органами живых здоровых людей, а некоторые технологии воздействия на сознание могут привести и к исчезновению Гомо сапиенса как вида. В этом контексте актуально вспомнить, что в человеческом обществе регуляторы нравственности, золотое правило морали, принцип Парцельса «Не навреди» помогают и сохранить экологию. Принцип «Не навреди» близок тому, что на санскрите звучит как «ахимса». Оно предполагает поведение, которое первым требованием включает недопустимость насилия, в чем бы оно не выражалось (Schmidt, 1968; Tähtinen, 1976). Это одна из основ индийской философии с древних времен (Иитман, 1985). Мы видим проявление этого принципа в буддизме, джайнизме, индуизме и йоге, что заметно и в вегетарианской диете, и в других формах (Alsdorf, 2010). В политической жизни стран для предотвращения войн, которые приносят немалый вред экологии, может использоваться и данный принцип.

В брахманизме многие животные считаются священными, и преступлением является причинение им вреда. Известно, что это корова, обезьяна, слон, королевская кобра, птица Гаруда. Святость животных охраняется законом и религиозными учениями. Тот, причинит вред корове, в Индии может сесть в тюрьму, а убийство этого священного животного когда-то каралось смертной казнью. Человек, причиняющий вред слону, мог оказаться проклятым. Издевательство над животными могло оказаться причиной рождения в низших кастах и даже растениях и предметах. Почтительное отношение к животным в Индии - следствие религии индуизма. Исповедующие ее люди верили в переселение душ, при котором в теле животного могла поселиться душа человека, прич ем, и прямого родственника. Одна из философских опор вегетарианства - это теория о переселении душ. Мы видим, что культ животных восходит прежде всего к мифологическому и религиозному сознанию. Известно, что обожествление их представлено тотемизмом, космогоническими верованиями, а также зоолатрией. У самых разных народов при первобытнообщинном строе был распространен культ волка. Среди них тюрки, кельты, германцы, индусы, греки, народы Поволжья и Сибири. Волк ассоциировался с человеком, наделенным лидерскими качествами. При зоолатрии происходил метафорический перенос с одного объекта на другой. Причем, перенос был не только реальный, но желаемый, магический, когда люди верили, что поклоняющиеся получат силу и положительные качества того, кто является их культовым животным. У сибиря- ков, германцев, финнов, даже японцев встречался культ медведя. Известно, что ко- шек обожествляли в Аревнем Египте, ЯПпонии. Египтяне видели в этих животных напоминание о богине Баст, воплощавшей радость, плодородие, семью. Кошек, которые жили и умирали при храме, египтяне мумифицировали. В японском городе Кагосима был создан Храм Кошек. Об обожествлении животных создано много ученых трудов, эти темы являются также частями монографий, посвященных религи- 
озным верованиям. Среди них хочется выделить труд М. А. Коростовцева «Религия Аревнего Египта», в котором он, в частности, рассматривает египетские культы крокодила, священного быка Аписа, богини Таурт, предстающей в зооморфном образе гиппопотама и других представителей фауны (Коростовцев, 2000). Ученый проделал кропотливую работу, многоаспектно рассмотрев культ каждого священного животного Египта.

Надо заметить, что знания, полученные благодаря изучению древних религий, могут иметь воспитательное значение, поскольку информация об отношении предков к животным откладывается в подсознании, будит образы коллективного бессознательного. Аревние архетипы, становясь литературными образами, формируют ткань художественного произведения, несущего воспитательные функции. Трансформируясь в искусство, религиозные культы усиливают суггестию художественных произведений, моделирующих сознание реципиентов, заставляя их правильно относиться к природе, задумываться о причинах экологических катастроф.

Религия существует и для атеистов, но не как предмет веры, а как факт культуры, и в религиозных учениях есть много хорошего, в частности идеи уважительного отношения к животным, природе, непричинения вреда всему живому, мысли о возмездии за жестокое или неправильное отношение к природе и опасности его для жизни человека.

Таким образом, изучая разные религии и отношение к живой природе в различных культурах, мы можем прийти к выводу, что во всех уголках земного шара культурной нормой считалось уважение к природе, птицам и зверям, наличие его напрямую связывалось с сохранением и развитием жизни человека. Это было очень разумно, а потому и сегодня, в страшное время экологических катастроф, нам будет полезно вспомнить о культурном наследии человечества, накопившего большой опыт правильного отношения к природе. Вспомнив об этом, мы должны самое лучшее передать потомкам и как пример для подражания, и как информацию для размышления, и как древние образы в новых художественных формах, призванные воздействовать на сознание и подсознание людей, формируя у них правильное отношение к окружающему миру.

\section{СПИСОК АИТЕРАТУРЫ}

Кант, И. (1995) Критика практического разума / пер. с нем. СПб. : Наука. 528 с. $464 \mathrm{c}$.

Коростовцев, М. А. (2000) Религия Аревнего Египта. СПб. : Журнал «Нева» ; Аетний Сад.

Костина, А. В. (2005) Предмет и проблемное поле глобалистики // Знание. Понимание. Умение. № 3. С. 100-111.

Цитман, А. А. (1985) Современная индийская философия. М. : Мысль. 404 с.

Фромм, Э. (2007) «Иметь» или «быть». М. : АСТ ; АСТ-Москва. 320 с.

Шендрик, А. И. (2004) Глобализация в системе культурологических координат. Ч. 1 // Знание. Понимание. Умение. № 1. С. 59-70.

Alsdorf, L. (2010) The history of vegetarianism and cow-veneration in India. London : Routledge. $176 \mathrm{p}$.

Schmidt, H. P. (1968) The origin of ahimsa // Mélanges d'Indianisme à la mémoire de Louis Renou. Paris. P. 625-655.

Tähtinen, U. (1976) Ahimsa. Non-violence in Indian tradition. London. xii, 148 p. 
Иванова Ирина Сергеевна - кандидат философских наук, доцент, доцент кафедры философии, культурологии и политологии Московского гуманитарного университета. Адрес: 111395, Россия, г. Москва, ул. Юности, 5. Тел.: +7 (499) 374-61-81. Эл. адрес: Lesnaya10@yandex.ru

Ivanova Irina Sergeyevna, Candidate of Philosophy, Associate Professor, Department of Philosophy, Culturology and Politology, Moscow University for the Humanities. Postal address: 5 Yunosti St., 111395 Moscow, Russian Federation. Tel.: +7 (499) 374-61-81. E-mail: Lesnaya10@yandex.ru

\section{Аля иитирования:}

Иванова И. С. Этическое и эстетическое отношение к природе в различных культурах и религиях [Электронный ресурс] // Горизонты гуманитарного знания. 2017, № 4. URL: http://journals. mosgu.ru/ggz/article/view/583 (дата обращения: дА.мм.гггг.). DOI: 10.17805/ggz.2017.4.8 